\title{
Pegaptanib Sodium
}

National Cancer Institute

\section{Source}

National Cancer Institute. Pegaptanib Sodium. NCI Thesaurus. Code C95230.

The sodium salt form of pegaptanib, a 28-mer RNA aptamer covalently linked to two branched 20-kD polyethylene glycol (PEG) chains, with anti-angiogenic activity.

Pegaptanib binds and blocks the activity of the extracellular vascular endothelial growth factor, specifically the 165-amino acid isoform (VEGF165). This prevents VEGF165 from binding to VEGF receptors, thereby blocking angiogenesis as well as preventing VEGF165induced increases in vessel permeability. VEGF165 is preferentially involved in pathological ocular neovascularisation. 